\title{
Pengaplikasian Dry Ice Untuk Pengendalian Cylas formicarius pada Ubi Ketela Rambat
}

\author{
Afni Kurnia Firmani ${ }^{1)}$, Subagiya2l dan Ato Sulistyo2l
}

\begin{abstract}
ABSTRAK
Cylas formicarius is the main pest of sweet potatoes especially in storage. Damage from the pest attacks can reduce yields up to $97 \%$ and even minor damage causes sweet potatoes cannot be consumed because they taste bitter and toxic. Warehouse pest control such as $C$. formicarius is generally carried out by fumigation. Dry ice is a solid $\mathrm{CO}_{2}$ that can be used as a fumigant to control warehouse pests. This study aims to determine the application of dry ice as fumigant and different storage places for $C$. formicaius in sweet potatoes. The variables observed C. formicarius population and mortality, weight loss, decrease in water content, level of damage to sweet potatoes and taste testing. The results showed that the population of $C$. formicarius in control higher than the other treatments, in the storage area in the population space $C$. formicarius is higher than in dark storage. Mortality in the treatment of giving dry ice reached $100 \%$ at the dose of $5 \mathrm{~g}, 10 \mathrm{~g}$ and $15 \mathrm{~g}$. Weight reduction and decrease in water content in sweet potatoes correlate with each other where in the control treatment changes in weight and water content are highest compared to other treatments. Storage places have no effect on weight loss and loss of water content in sweet potatoes. Taste of sweet potatoes before and after the shelf life with the dry ice application has not changed.
\end{abstract}

Keywords: Mortality, Level Of Demage, Attack

\section{PENDAHULUAN}

Ubi jalar merupakan salah satu makanan pokok. Tanaman ini berkontribusi sebagai bahan pangan global karena berperan penting sebagai sumber energi. Ubi jalar juga digunakan sebagai pakan ternak di banyak negara berkembang (Lokesh et al. 2017). Ubi jalar merupakan tanaman pangan yang berpotensi sebagai pengganti beras dalam program diversifikasi pangan karena efisien dalam menghasilkan energi, vitamin dan mineral, berdasarkan produktivitas per hektar, per hari dibandingkan dengan tanaman pangan lainnya (Richana 2013). Pemanfaatan ubi jalar sebagai bahan makanan olahan dan bahan baku Industri kian beragam dan permintaannya terus meningkat, Selain itu ubi jalar merupakan komoditas ekspor di berbagai negara seperti Jepang, Korea dan Timur Tengah.

Penanganan pasca panen ubi jalar sering dirasa kurang tepat, karena masih adanya beberapa masalah diantaranya keberadaan hama yang terbawa saat pemanenan. Menurut Odi et al. (2011), Cylas formicarius merupakan hama utama pada ubi jalar. Keberadaan hama $C$. formicarius di gudang dapat menurunkan kualitas dan kuantitas ubi jalar. Larva, pupa, dan imago tinggal di dalam umbi, sehingga kerusakan di bagian dalam umbi sangat merugikan. Kotoran hama yang terdapat pada umbi yang telah rusak menyebabkan rasa pahit, selain itu ubi yang terserang $C$. formicarius bersifat beracun sehingga tidak dapat dikonsumsi (Nani et al. 2005).

\footnotetext{
1) Mahasiswa S1 Program Studi Agroteknologi, Fakultas

Pertanian, Universitas Sebelas Maret

2) Staf Dosen Program Studi Agroteknologi, Fakultas

Pertanian, Universitas Sebelas Maret
}

Author Contact: subagiya@gmail.com
C. formicarius menyebabkan kerusakan mekanik pada ubi jalar yaitu berupa liang-liang gerekan kemudian hama akan berkembangbiak dan meletakkan telurnya, bila siklus hama ini terus berlangsung kerusakan akan lebih parah dan merusak seluruh ubi jalar ditempat penyimpanan. Kerusakan akibat serangan C. formicarius dapat mencapai 97\% (Issa et al. 2017).

Pengendalian hama gudang seperti $C$. formicarius umumnya dilakukan dengan fumigasi. Pengunaan fumigan seperti Metil Bromide (CH3Br), Sulfuryl Fluoride (SO2F2) dan Fosfin (PH3) dinilai berbahaya bagi kesehatan pangan, kerana residu yang dihasilkan (Monro 1969). Berdasarkan BPTP (2006) penggunaan fumigan ini harus mendapatkan pengawasan khusus oleh Departemen Pertanian dan Departemen Kesehatan. Menurut Lin-gun Liu (1984), salah satu alternatif yang aman sebagai bahan fumigan yaitu dry ice. Dry ice merupakan karbondioksida dalam bentuk padat. Dry ice lebih aman digunakan karena ramah lingkungan dan tidak meninggalkan residu sehingga aman bagi kesehatan pangan, ketika dry ice menyublim gas karbondioksida dilepaskan dan dapat membunuh hama tanpa meninggalkan sisa.

\section{METODE PENELITIAN}

Penelitian ini dilaksanakan pada bulan MeiAgustus 2018 di dan di Laboratorium EMPT, Fakultas Pertanian UNS dan di Sumber Solo. Bahan yang digunakan dalam penelitian ini yaitu ubi jalar Varietas Korea, imago $C$. formicarius dan dry ice. Alat yang digunakan yaitu timbangan analitik, plastik hitam dan plastik transparan, sealer, tea bag, toples plastik, kain berpori serta oven. 
Penelitian ini menggunakan Rancangan Acak Lengkap (RAL) 2 faktorial, dengan 8 perlakuan yang terdiri dari :

DOP1 = Kontrol tanpa dry ice penyimpanan gelap.

D0P2 = Kontrol tanpa dry ice penyimpanan dalam ruang.

D1P1 = Dry ice 5 gram penyimpanan gelap.

$\mathrm{D} 1 \mathrm{P} 2=$ Dry ice 5 gram penyimpanan dalam ruang.

D2P1 = Dry ice 10 gram penyimpanan gelap.

$\mathrm{D} 2 \mathrm{P} 2$ = Dry ice 10 gram penyimpanan dalam ruang.

D3P1 = Dry ice 15 gram penyimpanan gelap.

D3P2 = Dry ice 15 gram penyimpanan dalam ruang.

Masing-masing perlakuan diulang 4 kali. Tiap perlakuan digunakan ubi jalar seberat kurang lebih $1 \mathrm{~kg}$ dan di investasi imago $C$. formicarius sebanyak 20 ekor yang terdiri dari 10 jantan dan 10 betina. Variabel pengamatan pada penelitian ini meliputi populasi dan mortalitas $C$. formicarius, perubahan berat dan kadar air ubi jalar, tingkat kerusakan serta uji rasa. Data yang diperoleh dianalisis dengan uji $\mathrm{F}$ pada taraf $5 \%$ dan dilanjutkan dengan Duncan Multiple Range Test (DMRT) $5 \%$ bila berbeda nyata.

\section{HASIL DAN PEMBAHASAN}

\section{Populasi dan Mortalitas $C$. formicarius}

Pengamatan dilakukan dengan menghitung C. formicarius yang hidup maupun yang mati untuk mengetahui populasi $C$. formicarius total (Nt). Uji mortalitas dilakukan dengan menghitung banyaknya C. formicarius yang mati untuk mengetahui efektivitas dry ice. Populasi total dan mortalitas C. formicarius pada tiap perlakuan dapat dilihat pada Gambar 1.

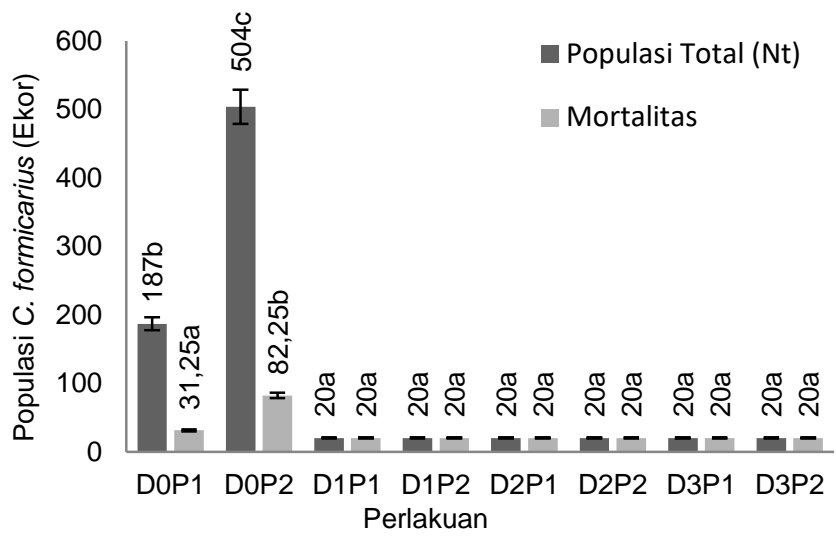

Gambar 1 Histogram pengaruh dry ice terhadap populasi dan mortalitas $C$. formicarius

Populasi $C$. formicarius tertinggi pada perlakuan kontrol D0P1 dan D0P2. Tempat penyimpanan berbeda nyata terhadap populasi $C$. formicarius pada perlakuan kontrol. Diduga hal tersebut disebabkan oleh faktor lingkungan yang berpengaruh terhadap perilaku C. formicarius dan menghambat perkembangbiakannya. Namun menurut Toru dan Seiici (1996) ritme cahaya tidak berpengaruh terhadap aktifitas C. formicarius tetapi dipengaruhi oleh ritme harian. Populasi $C$. formicarius pada perlakuan pemberian dry ice tidak terjadi perubahan dari investasi awal. Tingginya populasi $C$. formicarius pada perlakuan kontrol disebabkan oleh ketersediaan makanan yang cukup sehingga keberlanjutan hidup hama dapat terus berlangsung. Tantawijal et al. (2015) menambahkan perkembangbiakan $C$. formicarius tergolong sangat cepat. Seekor betina mampu bertelur 3-4 butir telur per hari atau 100-200 butir telur selama hidupnya, imago C. formicarius betina rata-rata dapat bertahan hidup hingga 75-105 hari.

Mortalitas C. formicarius pada perlakuan pemberian dosis dry ice $5 \mathrm{~g}, 10 \mathrm{~g}$ dan $15 \mathrm{~g}$ mencapai $100 \%$ dalam masa fumigasi 3 hari seperti terlihat pada gambar 1. Faktor-faktor yang mepengaruhi efikasi fumigasi yaitu spesies hama sasaran, siklus hidup hama (Hallman dan Thomas 2011), komoditas, dosis fumigasi dan suhu fumigasi (Phillips et al. 2015). Menurut Dadang dan Djoko (2008), tingkat kematian serangga dapat berlangsung dengan cepat setelah aplikasi fumigan, hal ini disebabkan karena serangga akan menghirup gas $\mathrm{CO}_{2}$ sehingga akan terjadi gangguan pada sistem respirasinya dan menyebabkan serangga keracuna. Selanjutnya serangga akan mengalami kelumpuhan dan akhirnya mati. Mortalitas C. formicarius terjadi akibat pemberian dry ice sebagai bahan fumigan. Dry ice akan menyublim menjadi gas sehingga $\mathrm{CO}_{2}$ dilepaskan dalam ruang kedap udara yang mengakibatkan kadar $\mathrm{CO}_{2}$ meningkat. Dalam waktu yang lama oksigen didalam ruang akan menurun karena dipergunakan serangga (hama) maupun produk yang disimpan untuk proses respirasi sedangkan kadar $\mathrm{CO}_{2}$ akan semakin meningkat. Meningkatnya konsentrasi $\mathrm{CO}_{2}$ dalam ruang kedap udara akan menyebabkan kematian serangga hama (Noomhorm et al. 2013). Changlu et al. (2012) menambahkan, kematian serangga hama disebabkan kadar $\mathrm{CO}_{2}$ yang meningkat menyebabkan spirekel serangga tetap terbuka, sehingga serangga mengalami dehidrasi.

\section{Perubahan Berat Ubi Jalar}

Berat ubi jalar diukur untuk mengetahui perubahan berat akibat serangan $C$. formicarius. Perubahan berat ubi jalar diketahuai dengan cara menimbang berat ubi jalar awal (sebelum disimpan) dan akhir (setelah disimpan). Perubahan berat ubi jalar dapat dilihat pada Tabel 1.

Tabel 1 Perubahan berat ubi jalar selama 2 bulan penyimpanan

\begin{tabular}{lccr}
\hline Perlakuan & \multicolumn{2}{c}{ Berat } & \multicolumn{1}{c}{$\begin{array}{c}\text { Perubahan } \\
\text { Berat }(\mathrm{g})\end{array}$} \\
\cline { 2 - 3 } & Awal $(\mathrm{g})$ & Akhir $(\mathrm{g})$ & \multicolumn{1}{c}{ Ber } \\
\hline D0P1 & 1023,71 & 348,02 & $675,68 \pm 39,30 \mathrm{~b}$ \\
D0P2 & 1037,23 & 288,52 & $748,71 \pm 10,12 \mathrm{c}$ \\
D1P1 & 1017,35 & 982,77 & $34,57 \pm 11,19 \mathrm{a}$ \\
D1P2 & 1022,24 & 986,47 & $35,77 \pm 10,00 \mathrm{a}$ \\
D2P1 & 1006,25 & 961,17 & $45,10 \pm 12,79 \mathrm{a}$ \\
D2P2 & 1015,19 & 963,76 & $51,43 \pm 18,01 \mathrm{a}$ \\
D3P1 & 1031,49 & 980,30 & $51,19 \pm 30,64 \mathrm{a}$ \\
D3P2 & 1017,72 & 975,38 & $42,34 \pm 12,91 \mathrm{a}$ \\
\hline
\end{tabular}

Keterangan: Angka-angka yang diikuti huruf yang berbeda pada kolom yang sama menunjukkan berbeda nyata berdasarkan DMRT pada taraf $5 \%$. 
Perubahan berat ubi jalar pada perlakuan kontrol dan pemberian dosis dry ice berbeda nyata. Pada perlakuan kontrol perubahan berat lebih besar dibandingkan dengan perlakuan pemberian dry ice. Pada perlakuan DOP2 terjadi perubahan berat paling tinggi yaitu $748,71 \mathrm{~g}$ dan perubahan berat tertinggi kedua pada perlakuan D0P1 yaitu 675,68 . Perubahan berat ubi jalar pada perlakuan kontrol yang besar ini diduga disebabkan oleh kerusakan yang disebabkan oleh C. formicarius. Menurut Noritha et al. (2013) C. formicarius merusak ubi jalar dengan cara menggerek dan membuat liang-lianng, sehingga mengakibatkan kerusakan dan kehilangan hasil. Perubahan berat ubi jalar pada perlakuan pemberian dry ice berkisar antara 34-52 gram. Perubahan berat ubi jalar pada perlakuan pemberian dry ice disebabkan karena kehilangan kadar air dan bukan disebabkan karena serangan $C$. formicarius. Sebab pada perlakuan pemberian dry ice mortalitas $C$. formicarius mencapai $100 \%$. Menurut Chaitali et al. (2017), penurunan kadar air pada ubi jalar diakibatkan prose evaporasi yang dapat menurunkan berat.

\section{Perubahan Kadar Air Ubi Jalar}

Pengukuran kadar air ubi jalar dilakuakn di awal (sebelum masa simpan) dan di akhir (setelah masa simpan). Pengukuran kadar air dilakukan dengan metode termogafrimetri. Perubahan kadar air ubi jalar dapat dilihat pada Tabel 2.

Tabel 2 Perubahan kadar air ubi jalar selama 2 bulan penyimpanan

\begin{tabular}{lccr}
\hline Perlakuan & \multicolumn{2}{c}{ Kadar Air } & $\begin{array}{c}\text { Perubahan } \\
\text { Kadar air (\%) }\end{array}$ \\
\cline { 2 - 3 } & Awal $(\%)$ & Akhir (\%) & Kadar \\
\hline D0P1 & 72,63 & 61,33 & $11,30 \pm 0,02 \mathrm{~g}$ \\
D0P2 & 72,63 & 53,13 & $19,50 \pm 0,03 \mathrm{~h}$ \\
D1P1 & 72,63 & 69,21 & $3,42 \pm 0,01 \mathrm{~b}$ \\
D1P2 & 72,63 & 69,41 & $3,22 \pm 0,00 \mathrm{a}$ \\
D2P1 & 72,63 & 68,01 & $4,62 \pm 0,01 \mathrm{e}$ \\
D2P2 & 72,63 & 67,53 & $5,10 \pm 0,02 \mathrm{f}$ \\
D3P1 & 72,63 & 68,76 & $3,87 \pm 0,01 \mathrm{c}$ \\
D3P2 & 72,63 & 68,33 & $4,30 \pm 0,00 \mathrm{~d}$ \\
\hline
\end{tabular}

Keterangan: Angka-angka yang diikuti huruf yang berbeda pada kolom yang sama menunjukkan berbeda nyata berdasarkan DMRT pada taraf $5 \%$.

Kadar air pada tiap perlakuan berbeda nyata. Pada perlakuan kontrol yaitu DOP1 dan DOP2 menunjukkan perubahan kadar air yang lebih besar dibandingkan pada perlakuan lainnya hal ini diduga karena pengaruh dari serangan $C$. formicarius yang menyebabkan luka mekanik pada ubi jalar sehingga laju kehilangan kadar airnya lebih cepat dibandingkan dengan ubi jalar yang tidak terdapat luka mekanik. Perubahan kadar air pada perlakuan pemberian dry ice berbeda nyata, namun perubahan kadar air berkisar antara $3-5 \%$. Perubahan kadar air pada perlakuan pemberian dry ice murni disebabkan oleh proses fisiologi sebab pada perlakuan pemberian dry ice tidak ada $C$. formicarius yang mampu bertahan hidup. Pemberian dry ice pada bahan simpan tidak akan mempengaruhi kadar airnya, karena dry ice yang diaplikasikan hanya akan berubah wujud menjadi $\mathrm{CO}_{2}$ gas tanpa terbentuk senyawa lain. (Anonim 2016).

\section{Tingkat Kerusakan Ubi Jalar Akibat $\boldsymbol{C}$. formicarius}

Tingkat kerusakan ubi jalar akibat serangan C. formicarius dinyatakan dalam persentase. Kerusakan ubi jalar akibat $C$. formicarius berupa liangliang gerekan dari larva $C$. formicarius yang memakan umbi dan menyebabkan perubahan warna umbi menjadi gelap. Persentase kerusakan ubi jalar akibat C. formicarius dapat dilihat pada Tabel 3.

Tabel 3 Persentase kerusakan ubi jalar akbiat C. formicarius

\begin{tabular}{lc}
\hline Perlakuan & Tingkat Kerusakan $(\%)$ \\
\hline D0P1 & $100 \mathrm{~b}$ \\
D0P2 & $100 \mathrm{~b}$ \\
D1P1 & $0 \mathrm{a}$ \\
D1P2 & $0 \mathrm{a}$ \\
D2P1 & $0 \mathrm{a}$ \\
D2P2 & $0 \mathrm{a}$ \\
D3P1 & $0 \mathrm{a}$ \\
D3P2 & $0 \mathrm{a}$ \\
\hline
\end{tabular}

Keterangan: Angka-angka yang diikuti huruf yang berbeda pada kolom yang sama menunjukkan berbeda nyata berdasarkan DMRT pada taraf $5 \%$.

Kerusakan ubi jalar akibat $C$. fomicarius pada perlakuan kontrol DOP1 dan DOP2 mencapai 100\% hal tersebut didukung dengan pernyataan Chiranjeevi et al. (2003) yang mengatakan bahwa kerusakan ubi jalar akibat serangan C. formicarius dapat mencapai $100 \%$. Sebab pada perlakuan kontrol populasi C. formicarius sangat tinggi. Menurut Marida dan Yusmani (2016) kerusakan ubi jalar diakibatkan oleh larva $C$. formicarius yang merusak dengan cara membuat liang-liang gerekan pada daging umbi dan memakannya sampai terjadi perubahan siklus hidup menjadi pupa. Kibrom (2015) menambahkan, imago C. formicarius memakan epidermis daun dan memakan permukaan ekternal ubijalar sehingga menyebabkan luka tusukkan berbentuk bulat yang disebabkan oleh flagelum. Kerusakan ubi jalar akibat serangan $C$. formicarius pada ubi jalar dapat dilihat pada Gambar 1.

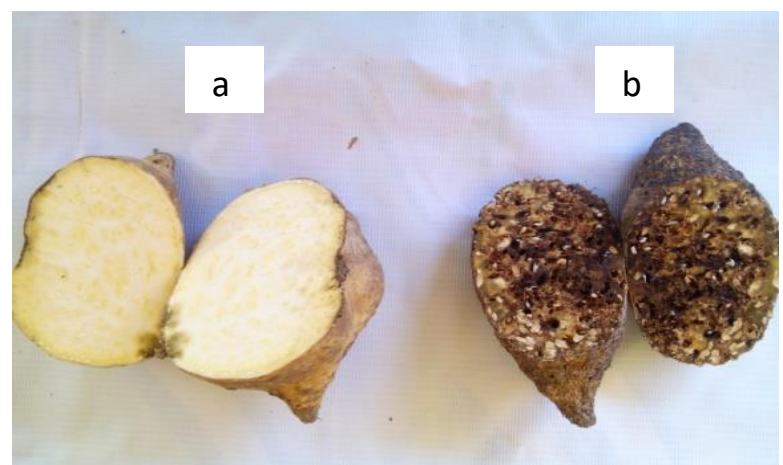

Gambar 1. Perbedaan ubi jalar yang tidak diserang C. formicarius (a) dan yang diserang $C$. formicarius (b)

Gambar a menunjukkan ubi jalar yang tidak diserang $C$. formicarius sedangkan gambar b 
menunjukkan ubi jalar yang diserang $C$. formicarius. Ubi jalar yang diserang $C$. formicarius tampak terdapat lubang-lubang gerekan yang didalamnya terdapat larva maupun pupa $C$. formicarius. Menurut Sri dan Nasir (2010), bekas gerekan larva $C$. formicarius pada ubi jalar akan berubah menjadi lebih gelap. Ubi jalar yang diserang oleh $C$. formicarius juga tampak mengalami kebusukan. Lokesh (2017) menambahkan, luka yang disebabkan oleh $C$. formicarius mengakibatkan infeksi sekunder mikroorganisme sehingga menyebabkan pembusukan umbi.

\section{Uji Rasa}

Pengujian rasa pada ubi jalar dilakukan sebelum dan setelah disimpan selama 2 bulan, hal ini bertujuan untuk mengetahui pengaruh aplikasi dry ice terhadap rasa ubi selama penyimpanan. Pengujian rasa melibatkan 10 responden. Ubi jalar yang akan diuji rasa sebelumnya dikukus agar rasa asli dari ubi jalar dapat dipertahankan.

Tabel 4 Uji rasa ubi jalar sebelum dan sesudah dismpan

\begin{tabular}{lcc}
\hline Perlakuan & \multicolumn{2}{c}{$\overline{\mathbf{x}}$} \\
\cline { 2 - 3 } & Sebelum & Sesudah \\
\hline D0P1 & 1,2 & - \\
D0P2 & 1,2 & - \\
D1P1 & 1,2 & 1,6 \\
D1P2 & 1,2 & 1,7 \\
D2P1 & 1,2 & 1,5 \\
D2P2 & 1,2 & 1,6 \\
D3P1 & 1,2 & 1,6 \\
D3P2 & 1,2 & 1,5 \\
\hline
\end{tabular}

Keterangan: 1=Sangat Enak, 2=Enak, 3=Cukup Enak, 4=Agak Enak, 5=Tidak Enak

Pengujian rasa pada ubi jalar sebelum disimpan dari 10 responden didapatkan nilai rata-rata 1,2 pada semua perlakuan. Artinya rasa ubi jalar sangat enak sebelum dilakukan penyimpanan. Ubi jalar yang diuji rasa sebelum disimpan dianggap homogen karena ubi berasal dari pertanaman dan masa panen yang sama.

Uji rasa pada ubi jalar setelah masa simpan 2 bulan pada perlakuan D2P1 dan D3P2 diperoleh ratarata 1,5 pada perlakuan D1P1, D2P2 dan D3P1 diperoleh rata-rata 1,6 sedangkan perlakuan D1P2 diperoleh rata-rata 1,7 . Dari semua perlakuan yang diuji rasa menghasilkan nilai rata-rata lebih dari 1,5 yang artinya rasa ubi jalar setelah penyimpanan memiliki rasa enak. Rasa ubi jalar tidak memiliki banyak perubahan setelah masa simpan dan pemberian perlakuan. Sehingga dry ice tidak berpengaruh terhadap rasa ubi jalar. Sedangkan pada perlakuan D0P1 dan D0P2 tidak dilakukan pengujian rasa karena ubi jalar pada perlakuan ini tidak layak untuk dikonsumsi akibat serangan $C$. formicarius dan dipastikan memiliki rasa sangat tidak enak. Menurut Noritha et al. (2013) ubi jalar yang terserang $C$. formicarius bila dikonsumsi terasa pahit. Rasa pahit ini disebabkan karena kotoran dari larva $C$. formicarius. Stathers et al. (2003) menambahkan, kerusakan kecil maupun besar akibat gerekan Cylas pada ubi jalar akan merangsang pembentukan senyawa toksik terpenoid sebagai reaksi ubi jalar terhadap serangan Cylas sehingga membuat rasanya tidak enak dan tidak bisa dikonsumsi. Senyawa racun yang terbentuk dapat mempengaruhi kerja hati dan paru-paru pada manusia dan mamalia

\section{KESIMPULAN}

1. Aplikasi dry ice pada penyimpanan ubi jalar mampu mengendalikan $C$. formicarius dengan mortalitas $100 \%$ pada dosis $5 \mathrm{~g}, 10 \mathrm{~g}$ dan $15 \mathrm{~g}$. Sehingga aplikasi dry ice paling efektif pada dosis $5 \mathrm{~g}$.

2. Aplikasi ubi jalar pada tempat gelap mampu menekan pertumbuhan $C$. formicarius dibandingkan dengan penyimpanan dalam ruang.

3. Aplikasi dry ice pada ubi jalar mampu menekan kerusakan hingga $0 \%$ pada dosis terendah yaitu $5 \mathrm{~g}$. Aplikasi dry ice tidak berpengaruh pada ubi jalar baik kualitas (rasa) maupun kuantitas

\section{DATAR PUSTAKA}

Anonim. 2016. Praxairmaterial safety data sheet product: solid carbon dioxide. USA: Praxair Thechology, Inc.

Balai Pengkaji Teknologi Pertanian (BPTP) Sumatra Selatan. 2003. Laporan penelitian dan pedoman penanganan pasca panen padi, Palembang. Kerja sama IRRI - SSFFMP - BPTP Sumatra Selatan.

CB Phillips, II lline, M Novoselov, et al. 2015. Methyl bromide fumigation and delayed mortality: safe trade of live pests. J of Pest Sci 88(1): 121-134. DOI: 10.1007/s10340-014-0573-7.

Changlu Wang, Lihua Lu, Ming Xu. 2012. Carbon dioxide fumigation for controlling bed bugsin. $J$ of Medical Entomology 1077-1083. DOI: 10.1603/ME12037.

Chaitali C, Rupsa R, Suravi C, et al. 2017. A review on post-harvest profile of sweet potato. Int $\mathrm{J}$ Curr Microbiol App Sci 6(5): 1894-1903. DOI:10.20546/ ijemas.2017.605.210.

Chiranjeevi C, Reddy DDR, Gour TB, et al. 2003. Comparative biology of sweet potato weevil Cylas formicarius Fabricius on vines and tubers of sweet potato. J of Research Angrau 31:17-21.

Dadang, Prijono D. 2008. Insektisida nabati, prinsip, pemanfaatan dan pengembangan. Bogor: Departemen Proteksi Tanaman IPB.

Hallman GJ, Thomas DB. 2011. Evaluation of the efficacy of the methyl bromide fumigation schedule against Mexican fruit fly (Diptera: Tephritidae) in citrus fruit. J Econ Entomol 104: 63-68. DOI: 10.1603/EC10199.

Issa M, Albert N, Lame Y. 2017. Insecticidal efficacy of neem (Azadirachta indica A. Juss.) products against the sweet potato (Ipomea batatas L.) weevil (Cylas puncticollis Boh.) in storage. J of Entomology and Zoology Studies 5(5):1130-1137.

Kibrom Beyene. 2015. Destitution, Biology, Yield Loss and Management of Sweet Potato Weevils (Cylas formicariuss (fabrcius) Insecta: Coleoptera) in 
Ethiopia. $\mathrm{J}$ of Biology, Agriculture and Healthcare 5(22):65-72.

Lin-gun Liu. 1984. Compression and phase behavior of solid $\mathrm{CO}_{2}$ to half a megabar. J Elsevier 71(1):104110. DOI: 10.1016/0012-821X(84)90056-6.

Lokesh KV, Kanmani S, Adline JD, et al. 2017. Adulticidal activity of nicotiana Tabacum linnaeus (Solanaceae) leaf extracts against the sweet potato weevil Cylas formicarius Fabricius 1798 (Coleoptera: Brentidae). J of Entomology Zoology Studies 5(5):518-524.

Marida S, Yusmani S. 2016. Pengendalian hama penggerek ubi jalar Cylas formicarius (Fabricus) (Coleoptera: Curculionidae) menggunakan cendawan entomopatogen Beauveria bassiana (Balsamo) Vuillemin. J Entomologi Indonesia. 13(1):40-48. DOI: 10.5994/jei.13.1.40.

Monro HAU. 1969. Manual of fumigation for insect control. Food and Agriculture Organization of The United Nations: Rome, Italy.

Nani Z, Minantyorini, Dodin K. 2005. Penyaringan ketahanan plasma nutfah ubi jalar terhadap hama lanas. Buletin Plasma Nutfah 11(1):11-15.

Noomhorn A, Sirisoontaralaka $P$, Uraichuen J, et al. 2013. Efficacy of atmospheric and pressurized carbon dioxide or air againts Sitophilus zeamais Motchulsky (Coleoptera:Curculionidae) and Tribolium castaneum (Herbst) (Coleoptera : Tenebrionidae) in milled rice. $\mathrm{J}$ of Stored Product Research 54:48- 53.
Noritha A,Odi R, Pinontoan,et al. 2013. Penyebaran hama Cylas formicarius F. pada tanaman ubi jalar (Ipomea batatas L.) di beberapa ketinggian tempat Provinsi Sulawesi Utara. Ejurnal 2(4):1-7.

Odi R, Pinontoan, Maxi Lengkong, et al. 2011. Hama penting tanaman ubi jalar (Ipomea batatas L.(Lamb)) di Kabupaten Minahasa, Minahasa Utara, dan Kota Tomohon. J Eugenia 12(7):114122.

Sri W, Nasir S. 2010. Hama boleng pada tanaman ubi jalar dan pengendaliannya. Buletin Palawija 19:2737.

Stathers TE, Rees D, Nyango A, Kiozya, et al. 2003 Sweet potato infestation by Cylas spp. in East Africa investigating the role of root characteristics. International $\mathrm{J}$ of Pest Management 49:141-146. DOI: 10.1080/0967087021000043094.

Richana. 2013. Mengenal potensi ubi kayu dan ubi jalar cet II. Bandung: Nuansa Cendekia.

Tantawizal, Alfi I, Yusmani P. 2015. Potensi cendawan entomopatogen Beauveria bassiana (Balsamo) Vuillemin untuk mengendalikan hama boleng Cylas formicarius F. Pada tanaman ubi jalar. Buletin Palawija 29:46-53.

Toru M, Seiichi M. 1996. Flight time and flight age in the sweet ptato weevil Cylas formicarius (Fabricius) (Coleoptera : Brentidae). J Entomol Zool 31(4):575-580. DOI: 10.1303/aez.31.575. 